\title{
Analysis of Cold protection, Conservation and Pest Control of Winter Garden Flowers
}

\author{
Zhang Yuyu, Liu Jiani, Xu Shengguang, Chen Zebin and Yu Lei* \\ Kunming University, Yunnan Province, Kunming 650214, China
}

Yunnan Urban Agricultural Engineering \& Technological Research Center, Yunnan Province, Kunming
650214, China

Key laboratory of Special Biological Resource Development and Utilization of Universities in Yunnan Province, Kunming 650214, China

Correspondence author: Yu Lei*

Keywords: Garden flowers; Cold protection and conservation; Pest control

\begin{abstract}
The utilization of flowers is crucial in garden construction, and it is the key to build the atmosphere and characteristics of gardens. In cold winter, flowers are easily subjected to freezing injury, so it is very important to do a good job of cold protection, conservation and pest control of winter garden flowers. Only when the high efficiency of flower conservation and management is ensured, will the garden landscape be ensured to be protected and optimized, therefore, this paper mainly carries on exposition with focus on cold protection, conservation and pest control of winter garden flowers, and conducts deep exploration from three aspects of conservation measures, cold-proof methods and pest control for early winter garden flowers, with the main purpose to reduce the impact of pest and disease damages on flower growth in cold climate.
\end{abstract}

\section{Introduction}

In recent years, with the rapid development of urbanization, the public's environmental awareness and greening awareness are constantly increasing. In garden construction, the utilization amount of flowers is the largest, and flowers together with shrubs, arbors and other plants constitute the beautiful garden landscape. In recent years, the winter weather has been very varied, and the phenomenon of continuous temperature reduction in autumn often appears, causing freeze injury to garden flowers. Given this, relevant managers need to pay attention to climate changes, and adopt effective protective measures to carry out cold protection and conservation on flowers, thus ensuring the healthy growth of flower plants, and providing a guarantee for the beauty of garden construction.

\section{Conservation measures for winter garden flowers}

\subsection{Irrigation on flower seedlings}

Flower seedlings need to be irrigated in early winter and early spring, and usually the irrigation will be done for two times, with the goal to avoid freeze injury in winter or dried top of seedlings in early spring, as the specific heat capacity of water is relatively high, water absorbs a lot of optothermal of sunlight without significant rise in temperature in the daytime, the surrounding soil temperature likewise will not dramatically rise due to high temperature; in the evening, with the continuous decrease of temperature, water can emit heat and freeze, thus coagulating heat energy, and avoiding soil temperature at bottom of the flower seedlings to be overly low, besides, the root temperature of the flower seedlings is kept within a stable range, so as to avoid cold injury on root system of the seedlings. Therefore, every early winter, generally in middle third of November, flowers should be irrigated, especially for newly planted flower seedlings, irrigation can effectively enhance cold-resistance of the plants. 


\subsection{Timely fertilization on flower seedlings}

In winter, many garden flower seedlings will stop growing, but their roots will usher in the peak of growth. Hence, in early winter, flower seedlings need to be fertilized for once. The fertilizer consumption is determined by the planted time and age of flower seedlings, the fertilizer is mainly chemical or organic fertilizer. Irrigation of some water is needed when applying fertilizer, so that the fertilizer can flow to the seedling root with water, thus promoting growth of the seedlings, and providing favorable conditions for future strong growth of the seedlings.

\subsection{Timely pruning on flower seedlings}

In winter, flower seedling growth is very slow, and attention needs to be paid to pruning of the seedling. In the process of pruning, the growing characteristics of the seedlings should be based, some feeble, exploit-based and withered branches should be pruned away, and proper pruning on eugonic branches should be done, which has a positive effect on the growth of other branches, and can change the ventilation situation between the branches, thus contribute to future growth of the seedlings.

\section{Cold-proof methods for garden flowers in winter}

The temperature is relatively low in winter, and it's windy and dry in spring. Hence, due to the large change range of climate, the healthy growth of garden flowers is easily affected. In particular, seedlings are easily subjected to freeze injury. In order to reduce the impact on garden flowers, some feasible cold-proof measures need to be adopted to ensure the healthy growth of flower seedlings.

\subsection{Soil-bury measure}

Some of the newly planted flower seedlings need to be buried with soil before early winter for freeze protection. The seedlings buried with soil and separated from the surrounding environment can be kept in a high temperature environment, so as to avoid freeze injury in winter. The application of this measure is very extensive, but the following problems need to be focused on when burying flowers with soil: first, suitable burying time needs to be chosen, which should be neither too early nor too late. Improper time will lead to rot of the flower seedlings, or cannot realize the protection against cold. Second, attention should be paid to thickness of the burying soil. Under normal circumstances, it is okay when the burying soil can cover up the seedlings. Third, the time of soil removal should be noted. Appropriateness of the time should be ensured, too early or too late soil removal will make the flower seedlings suffer from freeze injury or rot.

\subsection{Grass-cover measure}

The so-called grass-cover measure is to use wheat-straws, straws and cornstalks to cover up garden flowers. In general case, the time of covering grass will be after a snowfall, and the thickness of grass should be $4 \sim 5 \mathrm{~cm}$ higher than that of seedling top. Because the grass covered is very light and easily to be blown away, so straw rope or a layer of shallow soil is needed to cover the grass. The grass will be removed a week before lifting of seedlings in the following spring. Compared to soil-bury measure, the cost of grass-cover measure is relatively high and the anti-freezing effect is unsatisfactory.

\subsection{The setting of cold-proof windbreak}

In order to keep flower seedlings from being damaged by cold in winter, cold-proof windbreak can be deployed to prevent freeze injury. Under normal circumstances, corn stalks or relatively burly sorghum stalks will be used to produce cold-proof windbreak; if condition allowed, some cloth of colored strip or plastic cloth can be used to make the windbreak, the windproof and cold-proof effect is favorable, the service life is long, but more funds need to be invested. 


\subsection{Smoking measure}

The so-called smoking measure is to avoid frost by increasing the surface temperature. Most of the work will be done at the night before frost. The materials used for smoking are wet corn stalks, branches and wheat straws, which are usually deployed according to the density of 50 65pile /hm2, so as to meet the actual demand. The weight of the bonfire material needs to be controlled at $25 \mathrm{~kg}$ per pile. In the practice, small fire and big, dense smog need to be ensured until after the sunrise.

\section{Pest control methods for garden flowers}

In winter, when the temperature drops lower and lower, many insect pests that invade flowers will hibernate by various means, hence, diseases and insect pests are easily controlled in this period, and the period is the main phase for preventing diseases and insect pests of garden flowers. Practice has proved that pest control for flowers in winter can effectively lower the damage level of diseases and insect pests in the following year.

\subsection{Complete cleaning up of the garden plot}

The eggs or germs of many insect pests of flowers are hidden in fallen leaves and deadwood in the garden plot to live through the winter, and they will revive again to infringe flower plants until the following spring. Therefore, fallen leaves and deadwood in the garden plot need to be cleaned up in winter by means of centralized incineration, so as to change sanitary conditions in the growing area and to reduce the impact of diseases and insect pests on flowers. This method can obtain remarkable results in preventing powdery mildew of chrysanthemums, Chinese roses and crabapples, red spiders and anthracnose. In addition, according with the actual growth conditions of flower plants, pruning flowers in winter is also an effective way to avoid diseases and insect pests. After entering the winter, the dying, long or diseased branches of flowers should be pruned away and incinerated. This method can effectively prevent and control worm eggs on roses, Chinese roses and other flowers and trees, and be quite effective for pest control on flowers.

\subsection{Deep plowing on the garden plot}

In winter, deep plowing on land can injure pest larvae hidden in the soil, such as cutworms and grubs. The pest larvae can be exposed on land surface through deep plowing, and then the impact of diseases and pests on flower growth can be practically reduced by bird pecking or artificial killing. In addition, deep plowing can deeply bury the pathogens on strata surface into soil layer, and the pathogens in soil layer will be transferred to strata surface, so that the growing environment of the pests is destroyed, and the growth of them is effectively controlled. Furthermore, deep plowing is combined with drugs to prevent pest and disease damages. As pests are in dormancy period in winter, those diseases and pests difficult to be prevented in winter can be controlled with drugs, for example, black spot and rust disease occurred in winter can be controlled by $1 \%$ bordeaux spray and oil emulsion solution of 50 100 times, for successive 2 3 times, thereby effectively relieving the harm of diseases and insect pests in the following year.

\subsection{Whitewashing to protect branches}

The temperature is low in winter, and flowers are susceptible to harm of low temperature. In order to keep the regular growth of flowers from being affected, branches of flowers need to be whitewashed. Popular speaking, the branches need to be coated with some quicklime slurry, which can control diseases and insect pests, kill pests and protect flower seedlings from damages in winter, thus enhancing cold resistance and disease resistance of the seedlings, and effectively playing the dual effect of antifreezing and killing pests. Whitewashing on branches has favorable control efficiency on worm eggs or clam shells on the flower surface or hidden in the gaps. The quicklime slurry can only be used for whitewashing after ample dissolution, and the concentration should be appropriate, otherwise the branches will be damaged, and the healthy growth of flowers will be affected. In order to maintain the beauty of gardens, more attention should be paid to flowers. Only 
by ensuring the regular growth of flowers, will the public be able to enjoy the new look of garden scenery.

\subsection{Prevention and control by drugs}

Many pests are in hibernate state in winter, the prevention and control of which is relatively easy. But for pests relatively active in winter and difficult to be controlled, drug treatment is needed, which has relatively significant effect. For example, diesel oil emulsion and used oil can effectively control scale insects; pear rust and black spot can be effectively controlled in late winter by spraying 1\% Bordeaux mixture for 2 3 times. For drug treatment, the dosage of drugs sprayed should be noted, large dosage will cause burn injury to flowers, while too little dosage will be unable to play the preventive effect. Hence, when using drugs to prevent and control pests, the drugs should be prepared strictly in accordance with the drug instruction, lest the expected control objective is not achieved or the healthy growth of flowers is affected.

\section{Conclusion}

To sum up, the planting of flowers occupies a very important position in garden construction. In order to ensure the beauty of gardens, the integrity of flowers should be guaranteed. Only through continuous conservation and management, will the aesthetic sense of flower planting be ensured, so that the public can appreciate different beautiful sceneries of flowers in different periods. In order to prevent and control the diseases and pests of flowers, complete cleaning up and deep plowing of the garden plot and whitewashing need to be done, so as to ensure the healthy growth of flowers.

\section{References}

[1] Li Ningyi. Reflection on the practical teaching reform of horticulture and flower specialty [J]. Journal of Shenyang Agricultural Uinversity (Social Science Edition), 2015, 11 (04): 467-470.

[2] Liu Hongxia. Integrated control techniques for common diseases and insect pests of horticultural flowers [J]. Modern Horticulture, 2015, (20): 92.

[3] Wang Aifen. A brief analysis of the development trend of horticultural flowers in China [J]. Journal of Taiyuan City Vocational College, 2016, (09): 162-163.

[4] Guli Janati. Comprehensive pest control and overwinter management of horticulture and flower [J]. China Agricultural Information, 2015, (08): 98-99.

[5] Han Caixia. A study on tourism planning and design of flower gardens based on the industrial chain [D]. Shanxi University, 2017. 